\title{
UM ESTUDO SEMIÓTICO DAS ESTRATÉGIAS NARRATIVAS DA REVISTA EXAME ACERCA DAS COMUNIDADES VIRTUAIS
}

\section{A SEMIOTIC STUDY ABOUT EXAME MAGAZINE'S NARRATIVE STRATEGIES ON VIRTUAL COMMUNITIES}

Luís Alexandre Grubits de Paula Pessôa Instituto de Administração e Gerência da Pontifícia Universidade Católica do Rio de Janeiro IAG/PUC-Rio lpessoa@iag.puc-rio.br

Alessandra de Sá Mello da Costa Instituto de Administração e Gerência da Pontifícia Universidade Católica do Rio de Janeiro IAG/PUC-Rio alessandra.costa@iag.puc-rio.br

Paula Oliveira do Espírito Santo Instituto de Administração e Gerência da Pontifícia Universidade Católica do Rio de Janeiro IAG/PUC-Rio paula.oesanto@yahoo.com.br

Submissão: $16 / 05 / 2013$

Aprovação: 06/03/2015 


\title{
RESUMO
}

O presente artigo tem por objetivo proceder a uma aplicação do modelo teórico clássico da Semiótica Discursiva de linha francesa para identificar as estratégias narrativas e discursivas adotadas pela revista Exame em seu discurso sobre as comunidades sociais virtuais. Os resultados da análise evidenciam procedimentos de manipulação - por sedução e por intimidação - do destinatário-leitor pelo destinador-revista, além de identificar o culto a símbolos e personagens emblemáticos do mercado empresarial. Constata-se, adicionalmente, que a instrumentalização das comunidades virtuais constitui peça relevante do discurso sobre tecnologias gerenciais construído pela revista.

Palavras-chave: Comunidades virtuais. Semiótica. Revistas de negócios.

\begin{abstract}
The current article has the objective of offering an application of the classic theoretical model of the French Semiotics to identify narrative and discoursive strategies employed by Exame Magazine in its dissertation about social virtual communities. The results of the analysis show evidence of manipulation of the Addressee by the Addresser, through seduction and intimidation, in addition to identifying an exaltation of emblematic symbols and characters from the business market. Furthermore, it is observed that the instrumentalization of virtual communities represents a significant piece of discourse about managerial technologies developed by the magazine.
\end{abstract}

Keywords: Virtual communities. Semiotics. Business magazines. 


\section{Introdução}

Lojas mediadas por computadores, comunidades virtuais que criam e endossam comportamentos de consumo, teias de relacionamentos no ciberespaço. Sedução? Persuasão? Manipulação? Como argumenta Castells (1999), desde o final do século passado, as tecnologias da informação estão (re)modelando a base material da sociedade em ritmo acelerado. E, nesse movimento, o desenvolvimento tecnológico torna-se cada vez mais persuasivo, tanto no que diz respeito ao crescente número de pessoas que fazem uso das novas tecnologias quanto no que se refere às diferentes atividades que também as utilizam (BAGOZZI; DHOLAKIA, 2002).

De forma um pouco mais específica, as mudanças produzidas pelo avanço das tecnologias de comunicação e informação promovem significativos desdobramentos no que diz respeito às relações comerciais e às transações de mercado - agora transferidas para o ambiente de rede on-line (SOUZA; FILENGA; SANCHEZ, 2011). Superando limitações geográficas e temporais, este ambiente virtual e social representa as relações e interações entre indivíduos e - como decorrência - o meio de propagação de informação, ideias e influências (KIMURA; MARTIN; BASSO, 2006). Assim, concomitante ao crescimento desse ambiente colaborativo e integrativo desencadeado pela facilidade de troca de informações via Internet, ocorre o aumento da importância das comunidades virtuais como formadoras de opinião (DALMORO et al., 2010).

Apesar de ainda não haver consenso acerca da definição de comunidade virtual (SIMÕES; SANT’ANNA, 2010), assume-se nesta pesquisa que estas podem ser definidas, de forma geral, como um agrupamento social proveniente da Internet e, de forma mais específica, como um grupo de consumidores que se encontram e interagem on-line em prol de sua realização pessoal e dos objetivos comuns de seus membros (DHOLAKIA; BAGOZZI; PEARO, 2004). Twitter, Facebook, MySpace ou Orkut, de qualquer forma, como defende Levy (1999, p. 127), o desenvolvimento dessas comunidades virtuais "se apoia na interconexão [...] [e] são construídas sobre as afinidades de interesses, de conhecimentos, sobre projetos mútuos, em um processo de cooperação ou de troca, independente das proximidades geográficas e das filiações institucionais".

Neste contexto de sentimento de experiência e responsabilidade compartilhada, as comunidades virtuais - viabilizadas e potencializadas pelas aplicações e ferramentas das 
novas mídias sociais - passam a exercer uma função primordial de mercado (uma vez que "podem ajudar a satisfazer as necessidades dos consumidores no que diz respeito ao compartilhamento de recursos, ao estabelecimento de relações, às trocas e à vivência de fantasias" (DALMORO et al., 2010, p. 5).

No caso do Brasil, a sua população on-line (incluindo quem se utiliza de computadores públicos, lan houses e acessos a partir de escolas e universidades) abrange cerca de 73 milhões de indivíduos (IBOPE Nielsen OnLine, 2011). Ainda de acordo com essa mesma fonte, a subcategoria comunidades, na qual se enquadram as redes sociais virtuais, blogs, bate-papos, fóruns e outros sites de relacionamento, envolvia, em maio de 2010, $87 \%$ do total de usuários ativos da Internet no País. Corroborando essas informações, Fialho e Lütz (2011, p. 6) destacam que "o Brasil é o país com maior número de usuários em redes sociais, em que mais de $80 \%$ da população acessa com frequência algum tipo de página de relacionamento, website colaborativo ou blog”. Simões e Sant'Anna (2010) complementam esse argumento afirmando que "o Brasil é o país que mais participa de comunidades virtuais, tanto em relação à concentração de usuários, quanto em relação ao tempo dispensado pelos brasileiros a este ambiente".

Em contrapartida, diante desse cenário, as empresas enfrentam um novo desafio: como instrumentalizar as redes sociais virtuais de modo a integrá-las aos processos e ferramentas de gestão já em uso? As revistas de negócios (publicações que possuem como temática os negócios e a gestão empresarial) identificam essa lacuna e apropriam-se do tema, divulgando e legitimando suas próprias abordagens e práticas de instrumentalização. Vinculadas à mídia popular, de uma forma geral, essas revistas cumprem um papel de produtoras e disseminadoras de discursos: (1) como gênero de circulação (artefatos do sentido de tornar público); e (2) como conteúdo (em relação àquilo que está impresso). Nesse sentido, ao veicularem as suas notícias, as revistas de negócios limitam e norteiam um universo de possibilidades colocadas à disposição dos leitores sendo consideradas, por estes, como um meio legítimo para se conhecer a realidade social.

Portanto, tendo em vista a capacidade das revistas de negócios de refletir e influenciar as práticas de gestão empresarial, o presente artigo tem por objetivo proceder a uma aplicação do modelo teórico clássico da Semiótica Greimasiana para identificar as estratégias narrativas e discursivas adotadas pela revista Exame em seu discurso sobre as comunidades sociais virtuais. 
De forma a atingir este objetivo, o presente artigo foi dividido em cinco seções. Após esta introdução, são abordados no referencial teórico a Semiótica Discursiva de linha francesa (definição, campo de estudo e o percurso gerativo de significação) e as revistas de negócios inseridas no escopo maior do pop-management. Na terceira seção, são apresentados os procedimentos metodológicos de coleta e análise dos dados para, na seção posterior, serem feitas as análises. Na quinta - e última seção - são apresentadas as considerações finais.

\section{Referencial teórico}

\subsection{Sobre a Semiótica Discursiva de linha francesa}

\subsubsection{Definição e campo de estudo}

O campo de estudos da Semiótica é compartilhado por diversas correntes teóricas como a Pierciana, a Russa e a Francesa - cada qual apresentando propostas epistemológicas e metodológicas próprias. Este trabalho vincula-se à perspectiva teórica da Semiótica Discursiva de linha francesa (de agora em diante, nomeada apenas de Semiótica), fundada por Algirdas Julien Greimas, também conhecida como Semiótica Greimasiana ou, ainda, Semiótica da "Escola de Paris", em função da concentração, nessa cidade, desde a década de 1960, de pesquisadores que trabalharam com Greimas ou em torno de seu pensamento. Segundo Greimas e Courtés (2008, p. 455),

a teoria semiótica deve apresentar-se inicialmente como o que ela é, ou seja, como uma teoria da significação. Sua primeira preocupação será, pois, explicitar, sob forma de construção conceitual, as condições da apreensão e da produção do sentido.

Na década de 1960, a Semiótica constituiu-se no campo epistemológico do estruturalismo, na confluência entre a Linguística, a Antropologia e a Filosofia. Os princípios fundadores da metodologia da Semiótica foram extraídos das obras de Ferdinand de Saussure e de Louis Hjelmslev. É importante considerar que o desenvolvimento da Semiótica integrou progressivamente a linguística da enunciação de Émile Benveniste, superando o "puro formalismo". Sobre esse aspecto, Bertrand (2003, p. 18) observa que 
a concepção semiótica do discurso, visto como uma interação entre produção (por um sujeito enunciador) e apreensão (ou interpretação, por um outro sujeito enunciador), foi pouco a pouco se aproximando da realidade da linguagem em ato, procurando apreender o sentido em sua dimensão contínua e estreitando cada vez mais o estatuto e a identidade de seu sujeito [...].

Sobre a ligação com a Antropologia Cultural, pode-se destacar a visão de que os usos culturais do discurso modelam o uso da linguagem pelo sujeito falante. As duas disciplinas enfatizam, portanto, os rituais, os hábitos e os motivos sedimentados na práxis coletiva das linguagens. Assim como Claude Lévi-Strauss, Greimas retomou e ampliou as pesquisas de Vladimir Propp sobre o conto e a literatura oral (HÉNAULT, 2006), aprofundando a definição das leis que regem a narrativa - a forma mais amplamente transcultural dos discursos - e sua influência na organização do imaginário humano.

Na Filosofia fenomenológica de Edmund Husserl e Marcel Merleau-Ponty, está a origem da reflexão semiótica sobre as relações entre o inteligível e o sensível nos processos de significação. A preocupação de Greimas com a relação entre um sujeito sensível e o objeto percebido, na esfera da percepção (o "não linguístico"), faz-se presente ao longo de sua obra, sobretudo em seu último livro, De l'imperfection, publicado em 1987.

Desde os seus primórdios, a Semiótica é caracterizada pela extensão progressiva - e considerável - de seu campo de investigações: partindo da análise da literatura oral (mitos, contos, rituais, etc.), rapidamente se interessou pela literatura escrita e pelo conjunto de discursos verbais (histórico, jurídico, filosófico, científico, etc.), abrangendo os discursos não verbais como a imagem fotográfica, a pintura, a escultura, a arquitetura, a música, bem como os discursos sincréticos, que organizam vários sistemas semióticos simultaneamente cinema, teatro, comunicação publicitária e mesmo comportamentos. Observa-se, portanto, que a Semiótica pretende adotar como objeto não somente as produções verbais e não verbais atribuíveis aos enunciadores, mas também os comportamentos humanos da vida cotidiana (hábitos e estilos de vida, por exemplo).

Na década de 1980, inicia-se um processo que altera o contexto no qual evoluem as ciências da linguagem. Segundo Fontanille (2007), a Semiótica Discursiva de linha francesa experimentou, desde então, o desenvolvimento de diversas pesquisas em perspectivas divergentes e, por vezes, até mesmo polêmicas. Nesse contexto, destacam-se os trabalhos de Semiótica Visual de Jean-Marie Floch (1985) e de Sociossemiótica de Eric Landowski 
(2004). Este trabalho é delimitado à aplicação de algumas ferramentas do modelo teórico canônico da Semiótica, apresentadas a seguir.

\subsubsection{O percurso gerativo da significação}

O percurso gerativo da significação pode ser definido como um modelo teórico da significação em um nível de generalidade que permite abordar toda a produção humana significativa, verbal e não verbal. O percurso gerativo da significação é um modelo estratificado, composto por uma sucessão de níveis distintos, desde o mais profundo e mais abstrato (sintaxe e semântica fundamentais) até o mais superficial e concreto (sintaxe e semântica discursivas), aquele dos discursos manifestados nas diferentes linguagens verbais e não verbais. $\mathrm{O}$ esquema do percurso pode ser identificado na Tabela 1, a seguir:

Tabela 1 - Percurso gerativo

\begin{tabular}{|c|c|c|c|}
\hline \multirow{2}{*}{ Estruturas semionarrativas } & Nível profundo & Sintaxe fundamental & Semântica fundamental \\
& Nível de superfície & $\begin{array}{c}\text { Sintaxe narrativa de } \\
\text { superfície }\end{array}$ & Semântica narrativa \\
\cline { 2 - 4 } & \multicolumn{2}{|c|}{$\begin{array}{c}\text { Sintaxe discursiva: } \\
\text { discursivização } \\
\text { (actorialização, } \\
\text { temporalização, } \\
\text { espacialização) }\end{array}$} & $\begin{array}{c}\text { Semântica discursiva: } \\
\text { tematização } \\
\text { figurativização }\end{array}$ \\
\hline
\end{tabular}

Fonte: Greimas e Courtés (2008, p. 235).

Em cada um dos níveis do percurso gerativo, há um componente sintático e outro semântico. Sobre esse ponto, é fundamental compreender que

a distinção entre sintaxe e semântica não decorre do fato de que uma seja significativa e a outra não, mas de que a sintaxe é mais autônoma do que a semântica, na medida em que uma mesma relação sintática pode receber uma variedade imensa de investimentos semânticos. (FIORIN, 2006, p. 21)

No nível fundamental, a significação surge como uma oposição semântica simples como |natureza| versus |cultura| e |vida| versus |morte| -, articulada sintaticamente no modelo lógico denominado “quadrado semiótico” (GREIMAS; COURTÉS, 2008). 
No nível narrativo, a narrativa é organizada do ponto de vista de um sujeito. Nessa etapa, os actantes (papéis narrativos abstratos) percorrem uma sequência canônica, que compreende as fases de manipulação, ação e sanção (GREIMAS; COURTÉS, 2008). A passagem dos níveis mais profundos aos superficiais faz-se por meio da operação fundamental de “conversão". Pela operação de conversão, um valor profundo do discurso será convertido no valor do actante-objeto procurado por um actante-sujeito (sintaxe e semântica narrativa de superfície) (BARROS, 2005).

Finalmente, no nível discursivo, a sintaxe e a semântica discursivas, graças à sustentação da enunciação (que vai colocar em discurso as estruturas semionarrativas de superfície), vão acrescentar significação ao discurso, convertendo os actantes em atores, introduzindo o tempo e o espaço.

Os procedimentos semânticos do discurso são dois: a tematização e a figurativização. Por meio dos percursos temáticos e figurativos, o enunciador assegura a coerência semântica do discurso e cria efeitos de sentido, sobretudo de realidade. Os temas e figuras decorrem de determinações sócio-históricas, conscientes ou inconscientes, que trazem para os discursos a maneira de ver e de pensar o mundo de grupos e classes sociais, o que faz da semântica discursiva "o campo da determinação ideológica propriamente dita" (FIORIN, 2004, p. 19). Barros (2004, p. 11) sintetiza as diferentes funções dos procedimentos de figurativização:

a figurativização assinala, com os temas, a determinação sócio-histórica e ideológica dos discursos; dá aos discursos temático-figurativos coerência semântica; participa, nos discursos temáticos, das estratégias de persuasão argumentativa, com figuras ocasionais e esparsas; concretiza os temas abstratos e produz efeitos de realidade; cria efeitos de concretização sensorial e dá "corporalidade" ao discurso e às relações entre enunciador e enunciatário; contribui para a produção de efeitos de novidade e criatividade estética, para dar prazer estético ao destinatário e para que enunciador e enunciatário partilhem instantes de "perfeição".

Embora o sentido do texto dependa da relação entre os três níveis do percurso gerativo da significação, cada um possui uma gramática autônoma, o que torna possível observá-los separadamente. 


\subsection{Revistas de negócios}

As revistas de negócios inserem-se no fenômeno de massa maior da mídia de negócios e da indústria do management, articulando e difundindo "uma visão de mundo particular, edificando idéias, comportamentos, projetos econômicos e políticos. [...]” (DIAS et al., 2007). Assim, alimenta um imaginário social específico e efetiva-se por meio de um processo de: (a) promoção de valores associados ao sucesso profissional; (b) indução pelo poder da influência e do prestígio de agendas específicas junto ao público executivo; (c) divulgação sistemática de novidades gerenciais; e (d) legitimação das novidades gerenciais (MICKLETHWAIT; WOOLDRIDGE, 1998; WOOD JR.; PAULA, 2001).

Segundo Spink (2004), as revistas, junto com jornais, arquivos, diários oficiais e registros, anúncios, publicidade, manuais de instrução e relatórios anuais, são documentos de domínio público e que, por isso, refletem duas práticas discursivas, quais sejam: (1) como gênero de circulação (artefatos do sentido de tornar público); e (2) como conteúdo (em relação àquilo que está impresso). Nesse sentido:

os documentos de domínio público são produtos sociais tornados públicos [...] Eticamente estão abertos para análise por pertencerem ao espaço público, por terem sido tornados públicos de uma forma que permite a responsabilização [...]. Podem refletir as transformações lentas em posições e posturas institucionais assumidas pelos aparelhos simbólicos que permeiam o dia a dia ou, no âmbito das redes sociais, pelos agrupamentos e coletivos que dão forma ao informal, refletindo o ir e vir de versões circulantes assumidas ou advogadas. (SPINK, 2004, p. 136)

Contribuindo com a discussão acerca das revistas de negócios como produtos sociais, Koller (2005) destaca a importância de se problematizar a questão dos discursos corporativos que são difundidos por reportagens, entrevistas e anúncios. Segundo Siqueira e Freitas (2006, p. 4), as grandes empresas servem como base para as reportagens ao mesmo tempo que compram os espaços para publicidade:

[...] Unibanco, Dell, Samsung, LG, Banco ABN Amro Real, Mercedes-Benz, BankBoston, Banco Bradesco, Microsoft, Volkswagen, IBM, Telefônica e Kodak fazem parte desse grupo de empresas que fazem publicidade na revista, definem o discurso organizacional [...] reproduzem a ideologia gerencial que interessam a elas e 'compram' umas das outras, técnicas que possam gerar maiores retorno a seus acionistas. 
Ainda de acordo com Koller (2005), esses discursos são mediados e controlados por canais como relatórios anuais, depoimentos e entrevistas que acabam por redobrar o poder econômico e político das corporações que controlam o acesso às suas informações, por exemplo, concedendo acesso preferencial aos jornalistas credenciados pelas próprias empresas para participarem de conferências de imprensa e entrevistas pré-agendadas com seus executivos. Como resultado, grande parte dos leitores das revistas somente tem acesso às informações por meio de filtros como estes (KOLLER, 2005).

No caso do Brasil, algumas revistas em específico adquirem maior importância como canal legitimador de práticas sociais (CAPELLE et al., 2003; SIQUEIRA; FREITAS, 2006), como é o caso da revista Exame (WOOD JR.; PAULA, 2002; 2006).

A revista Exame foi criada em 1971 tendo como referência a revista norte-americana Fortune cujo objetivo era "divulgar os fatos relacionados com as empresas, através das opiniões de empresários e exemplos de gestão empresarial” (DONADONE, 2000, p. 3). Apesar de em 1974 sofrer algumas mudanças (reforma editorial, fim da gratuidade e passagem de periodicidade mensal para quinzenal), o seu foco permanece em divulgar as estratégias empresariais, mas agora por meio da transcrição de artigos da também norteamericana Harvard Business Review. No entanto, de acordo com Donadone (2000, p. 4), foi a partir deste ano que o contexto econômico nacional e internacional - como o aumento das taxas de inflação, a indefinição dos rumos da economia e o choque do petróleo - passou a ser foco de preocupações de empresários e gerentes que "passaram a buscar maiores informações sobre o modo como os acontecimentos econômicos afetariam as empresas e suas aplicações financeiras".

Enfim, no decorrer dos anos 1980, a Exame adquire status de principal publicação da imprensa brasileira de negócios, desempenhando "o papel de principal fonte divulgadora de idéias sobre as modificações organizacionais e tecnológicas das empresas" (DONADONE, 2000, p. 4). Atualmente, além de oferecer matérias de interesse geral, a revista busca também relacionar fatos econômicos com seus impactos sobre as empresas, "divulgando sistematicamente novas tecnologias gerenciais" (WOOD JR.; PAULA, 2001, p. 6). 


\section{Procedimentos metodológicos}

Os dados foram coletados durante o segundo semestre de 2011 e entre as possibilidades de análise que o corpus selecionado permite, optou-se por um trabalho que pudesse representar a aplicação do modelo teórico clássico da Semiótica Greimasiana, contemplando o percurso gerativo da significação, oferecendo uma análise predominantemente narrativa e discursiva dos textos. Não serão tratadas, portanto, as relações simbólicas e semissimbólicas entre os planos do conteúdo e da expressão dos textos. Em outras palavras, pretende-se, aqui, analisar os procedimentos de manipulação do destinatárioleitor pelo destinador-revista de forma restrita ao plano do conteúdo.

É importante observar que, no contexto da tradição antropológica francesa, na qual se desenvolveu a Semiótica, o termo "manipulação" confunde-se com "comunicação". Com efeito, o fazer-comunicativo do destinador não se restringe apenas a um fazer-saber, mas acarreta um fazer-crer e um fazer-fazer, paralelo à interpretação no fazer-comunicativo do destinatário (BARROS, 2006). Dessa forma, neste trabalho, o emprego do termo "manipulação" está desvinculado de qualquer juízo moral que os usos cotidianos da palavra possam carregar.

Para viabilizar o objetivo proposto, foram separados metodologicamente os planos do conteúdo e da expressão das matérias jornalísticas. O estudo do plano do conteúdo contemplou as três etapas do percurso gerativo da significação, com ênfase nos níveis narrativo e discursivo. A análise foi conduzida dos pontos de vista sincrônico e diacrônico, considerando o corte cronológico de oito anos (2004 - 2011). Foram analisadas as seguintes matérias da revista de negócios Exame, conforme Tabela 2:

Tabela 2 - Dados coletados da revista de negócios Exame

\begin{tabular}{|l|l|l|}
\hline Título da matéria & Ano & Principais ferramentas abordadas \\
\hline A 140 toques dos consumidores & 2004 & Twitter \\
\hline Uma nova mania & 2004 & Orkut \\
\hline Tagarelas digitais & 2005 & Orkut \\
\hline O blog invadiu as empresas & 2005 & Blogs em geral \\
\hline Geração digital & 2005 & Orkut \\
\hline Os blogs vão mudar seus negócios & 2006 & Orkut e blogs em geral \\
\hline A web 2.0 invade as empresas & 2007 & $\begin{array}{l}\text { E-mail, Google Talk, MSN, Web mail, } \\
\text { Orkut, LinkedIn, Skype, Wikipedia, blogs }\end{array}$ \\
\hline Second Life? Que nada! & 2007 & Facebook \\
\hline A era da internet social & 2007 & Orkut, My Space, Facebook \\
\hline
\end{tabular}




\begin{tabular}{|l|l|l|}
\hline O Orkut dos investidores & 2007 & Orkut \\
\hline Pega um, pega geral & 2007 & Orkut e blogs em geral \\
\hline O enigma dos microblogs & 2008 & Twitter \\
\hline Cisco 3.0 & 2008 & Orkut, Wikipedia, Youtube \\
\hline O e-mail morreu & 2009 & Orkut, Twitter \\
\hline Um Orkut para chamar de seu & 2009 & Orkut \\
\hline Por que o Twitter merece atenção & 2009 & Twitter, Facebook, Orkut \\
\hline O boca-a-boca digital & 2009 & Facebook, Twitter \\
\hline $\begin{array}{l}\text { Por que nos rendemos a Twitter } \\
\text { (coluna Jack Welch) }\end{array}$ & 2009 & Twitter \\
\hline O poder das redes sociais & 2009 & Orkut, Facebook, My Space, Twitter \\
\hline A nova cara da felicidade & 2010 & Facebook, Twitter \\
\hline Uma história de cinema & 2010 & Facebook \\
\hline A rede social é o canal & 2011 & Redes sociais virtuais em geral \\
\hline $\begin{array}{l}\text { O Google também quer ser seu } \\
\text { amigo }\end{array}$ & 2011 & Orkut, Facebook, Google+ \\
\hline Da internet para a linha de produção & 2011 & Redes sociais virtuais e microblogs em geral \\
\hline Um olho na TV, outro no Twitter & 2011 & $\begin{array}{l}\text { Twitter, Redes sociais virtuais e microblogs } \\
\text { em geral }\end{array}$ \\
\hline
\end{tabular}

Fonte: Pesquisa de campo dos próprios autores.

\section{Análise dos dados}

\subsection{As narrativas da enunciação: o percurso da manipulação}

Observando o corpus do ponto de vista das narrativas da enunciação, o papel do destinador é preenchido pela revista, que manipula o leitor-destinatário - após fazê-lo crer na importância e na aplicabilidade das ferramentas tecnológicas consubstanciadas nas comunidades virtuais - a desempenhar a performance de adoção de tais ferramentas. Tal performance colocaria o destinatário em conjunção com o objeto valor "alinhamento com as recentes tendências de gestão".

Pode-se dizer que as ferramentas tecnológicas cumprem nessas narrativas a função de "objeto mágico" - que no conto maravilhoso aparece sob a forma de "varinha de condão", "espada" ou "tapete mágico" - e que coloca o sujeito em condições de entrar em estado de conjunção (poder-fazer) com o objeto-valor - "ir ao baile", "casar-se com a princesa" -, nesse caso, alinhar-se às mais recentes tendências de gestão. Nas matérias jornalísticas analisadas, o sentimento de falta que dá sentido à narrativa, na acepção de Propp (HÉNAULT, 2006), é o sentimento de urgência de acompanhar as inovações tecnológicas que, no discurso da mídia de negócios, transformam continuamente - e em grande velocidade - o ambiente de negócios. 
Com efeito, pode-se dizer que as narrativas das matérias analisadas assentam-se, no nível profundo do discurso, sobre a oposição semântica: |estabilidade| vs. |transformação|, conforme apresentadas na Figura 1 do quadrado semiótico abaixo.

Figura 1 - Quadrado semiótico: Nível fundamental do discurso

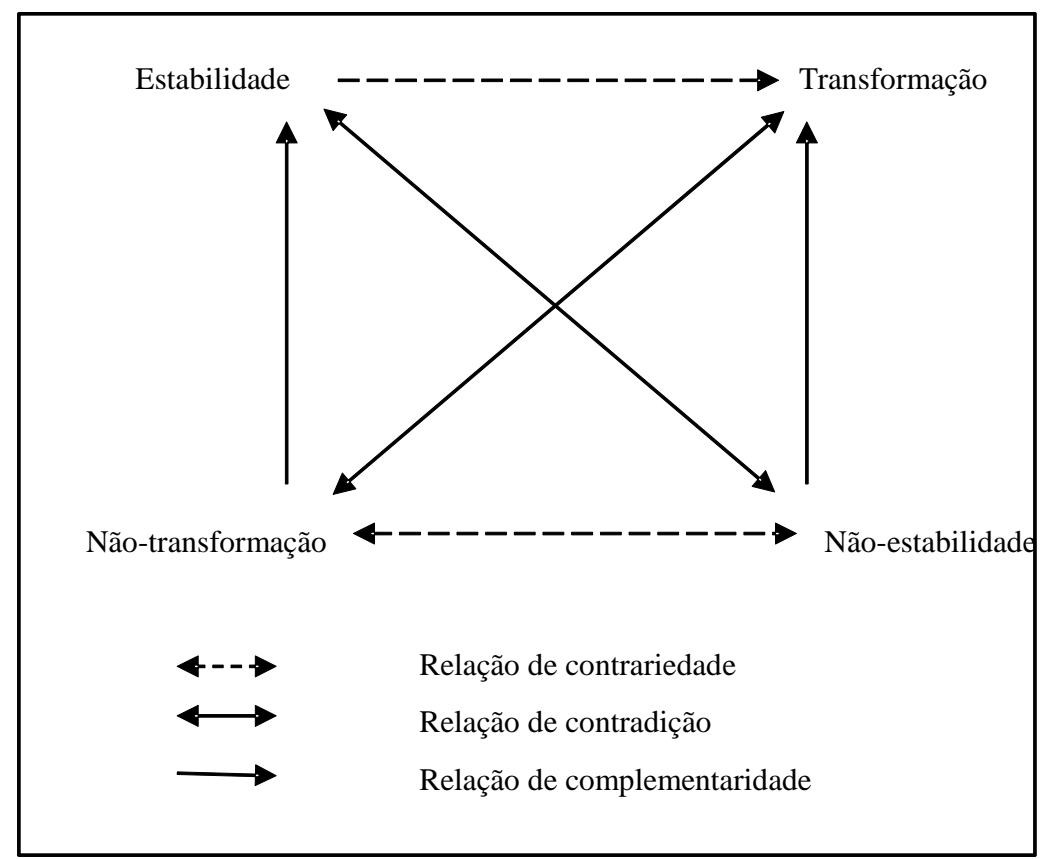

Fonte: Elaborado pelos autores a partir do modelo de Greimas e Courtés (2008).

Apesar de o conceito de acompanhar as tendências de gestão - a partir da adoção de ferramentas tecnológicas - ser dominante nas narrativas, observa-se, ao longo do período analisado, que as próprias tendências de gestão ganham outros sentidos nas matérias. Valores como a melhor compreensão das necessidades e desejos dos clientes e o relacionamento empresa-cliente são colocados em cena pelo destinador e, em alguns momentos, chegam a deslocar a tecnologia do centro do discurso.

O percurso do destinador pode ser desmembrado em duas etapas: (1) a atribuição das competências semânticas; e (2) a doação da competência modal.

$\mathrm{Na}$ doação da competência modal, que constitui a fase de manipulação em si, o destinador doa ao destinatário os valores modais do querer-fazer, dever-fazer, saber-fazer e poder-fazer. A atribuição das competências semânticas corresponde ao fazer persuasivo (fazer-crer), no qual o destinador, por meio, principalmente, de recursos do nível discursivo dos textos, apresenta-se como próximo e confiável e ao mesmo tempo poderoso (no sentido 
do conhecimento), fazendo o sujeito crer em sua capacidade de indicar as tendências de gestão.

No corpus analisado, a manipulação ocorre ora por sedução, ora por intimidação (nos casos em que os textos concentram-se nos riscos de ignorar as tendências), com o manipulador fazendo uso das competências do "saber" e do "poder" para seu fazerpersuasivo, o que leva o sujeito-destinatário a querer-fazer ou a dever-fazer algo, no caso, a adoção de determinada tecnologia. Tais estratégias são concretizadas nas narrativas dos enunciados e serão discutidas com mais detalhes na análise das matérias, na seção seguinte.

A contrapartida do fazer-persuasivo do destinador-manipulador é o fazerinterpretativo do sujeito que decorre da aceitação ou recusa do contrato proposto pelo manipulador. Tal interpretação é feita pelas modalidades veridictórias representadas na Figura 2 do quadrado semiótico:

Figura 2 - Quadrado semiótico: Modalidades veridictórias

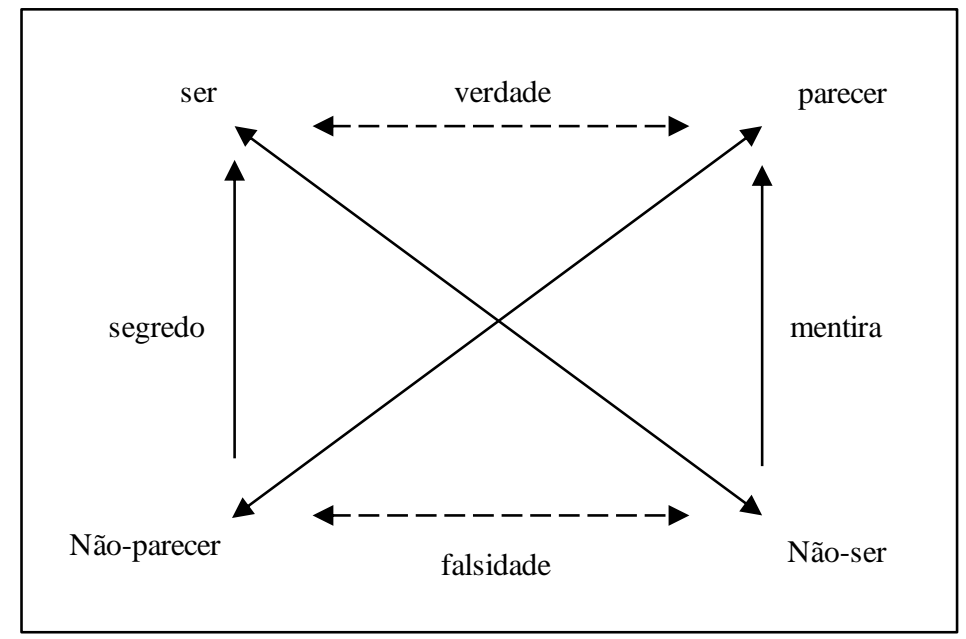

Fonte: Greimas e Courtés (2008, p. 532).

A aceitação pelo destinatário do contrato proposto depende da crença na veracidade do destinador e de seu discurso. Tendo em vista a estreita vinculação entre confiança e crença, o contrato entre destinador e destinatário pode ser definido como um contrato fiduciário, pois "a confiança entre os homens fundamenta a confiança nas palavras deles sobre as coisas e o mundo e, finalmente, a confiança ou crença nas coisas e no mundo" (BARROS, 2002, p. 37). 
Tanto o fazer-persuasivo quanto o fazer-interpretativo baseiam-se na competência semântica do destinador e do destinatário respectivamente, constituída por seus sentimentos, valores, crenças e conhecimentos. Segundo Barros (2006, p. 49):

[...] os sujeitos da comunicação não podem ser considerados como casas vazias e sim como casas cheias de projetos, aspirações, emoções, conhecimentos, crenças que vão determinar os modos de persuadir e as formas de interpretar. As estratégias de persuasão e as interpretações variam, assim, historicamente, de cultura para cultura, de sociedade para sociedade (de classe social para classe social). Fecha-se o círculo: os conhecimentos, crenças, sentimentos e valores dos sujeitos são resultantes de outras tantas relações de comunicação-manipulação-interação anteriores e vão-se modificando e construindo, portanto, outros sujeitos a cada nova relação de comunicação. São sujeitos dotados de outras competências, velhas e novas, modais e semânticas.

No caso da revista de negócios analisada, pode-se dizer, portanto, que a aceitação do contrato fiduciário pelo destinatário é facilitada pelo reconhecimento do éthos prévio do destinador, fruto de experiências e crenças anteriores do destinatário (sua experiência com a revista em questão e com outros produtos do segmento de negócios), e pela construção interdiscursiva de determinado texto com os que o antecederam.

Com efeito, as matérias de uma revista de negócios dialogam entre si, construindo, na perspectiva do destinatário, uma imagem consolidada do destinador. Considerando que as principais revistas do segmento de negócios estabelecem, além de suas identidades, a partir da interdiscursividade de seus textos, a identidade do segmento editorial como um todo, pode-se supor que os textos analisados neste trabalho apropriam-se do éthos coletivo do segmento editorial para facilitar a aceitação de seus contratos fiduciários.

Como ressaltado anteriormente, o fato de algumas publicações brasileiras, como a revista Exame, adquirirem maior importância como canal legitimador de práticas sociais não diminui a importância do discurso coletivo da mídia e de suas relações com outras expressões do discurso empresarial (SIQUEIRA; FREITAS, 2006; KOLLER, 2005), como a publicidade e a propaganda. Em função da aceitação ou não do contrato fiduciário entre destinador e destinatário, são observados os desfechos das narrativas, nos quais o destinatário pode ser sancionado positivamente ou negativamente. Nos textos analisados, a sanção positiva é caracterizada pela confirmação, por meio dos exemplos de empresas e executivos citados nos textos, de que determinado sujeito está alinhado com as principias tendências; enquanto a 
sanção negativa dá-se de forma mais sutil, em geral, pela ausência de empresas e gestores dos textos.

\subsection{As narrativas do enunciado: as estratégias de manipulação}

As narrativas dos enunciados podem ser definidas, de forma simplificada, como as "histórias contadas" nos textos analisados. Nesta etapa da análise, as narrativas são observadas de modo menos abstrato do que nas narrativas da enunciação, deixando mais evidentes as estratégias de manipulação do destinador, por meio de recursos de sedução e intimidação do destinatário. Deve-se observar que esse nível de análise, não raro, confunde-se com o nível discursivo, no qual as narrativas são assumidas pelo sujeito da enunciação, ganhando concretude temporal, actorial e espacial, em paralelo aos processos de tematização e de figurativização.

A leitura, em ordem cronológica, do conjunto de textos analisados deixa entrever a repetição dos seguintes atores no papel de sujeito das narrativas (ou das "histórias contadas"): consumidores, empresas de tecnologia (figurativizadas pelas suas soluções tecnológicas, como Twitter e Facebook) e empresas de outras áreas de atuação.

Se, nas narrativas da enunciação, é possível descrever um único processo de manipulação abstrato (descrito na seção anterior), no nível das narrativas dos enunciados a concretização da manipulação nas "histórias contadas" implica reconhecer sujeitos que interagem entre si e se revezam no papel de destinadores das "histórias" contadas nas matérias jornalísticas, conforme os exemplos a seguir apresentados.

O primeiro exemplo é o da matéria "Geração digital", publicada em 2005, na qual se estabelece o consumidor como destinador. Nessa matéria, o consumidor jovem é apontado como o grande formador de opinião e identificador de tendências no contexto da comunicação digital. A narrativa desenvolve-se com descrições de como funcionam as "comunidades virtuais", citando o Orkut como a plataforma mais utilizada, e o que as empresas tentam fazer para obter resultados no ambiente em questão.

Interessante observar que a matéria inicia-se com a descrição de cenas cotidianas de jovens entre 13 e 19 anos que utilizam as redes sociais de forma natural, para interagir com sua rede de relacionamentos e, após a discussão do impacto desse comportamento em 
diversos segmentos de mercado (apontando desafios, dúvidas e oportunidades para as empresas, com ilustrações de cases empresariais), encerra-se com uma ameaça explícita:

Para as empresas, é uma questão de escolha: seguir o caminho dessa geração ou permanecer à margem dele. Mas é melhor não perguntar a Julia, Luisa, Lucas, ou Ernesto [as mesmas personagens do início da matéria] nada sobre quem optou pela segunda alternativa. Dificilmente eles saberão de quem se trata (Matéria "Geração digital", 2005, p. 30).

O segundo exemplo é o da matéria "A era da internet social”, publicada em 2007, em que a empresa de tecnologia (figurativizada pela ferramenta) surge como destinador. Nesse texto, as comunidades sociais virtuais (como Orkut e Facebook) são descritas como principal "novidade" da internet desde o lançamento do Google. A narrativa desenvolve-se a partir da revisão das atividades de empresas do segmento de mídia e comunicação.

As dúvidas e desafios sobre o cenário da comunicação digital ainda estão presentes no texto, mas, ao contrário da matéria "Geração digital" (2005), nesse caso, a reportagem parte do pressuposto de que - nas palavras de Chris DeWolfe, criador do MySpace, uma das personagens da matéria:

as redes [desenvolvidas por empresas de tecnologia] serão cada vez mais a porta de entrada para a web (Matéria “A era da internet social”, 2007, p. 89).

Percebe-se claramente nessa matéria o culto de símbolos e figuras emblemáticas, uma das características da mídia de negócios (WOOD JR.; PAULA, 2001). São exemplos cabais o uso de Chris DeWolfe e de Mark Zuckerberg, bem como das empresas que criaram, MySpace e Facebook, respectivamente, como personagens da narrativa.

Como terceiro exemplo pode-se destacar a matéria "Da internet para a linha de produção", publicada em 2011, com a empresa no papel de destinador, que representa uma típica "história de final feliz", na qual a empresa Pepsico é sancionada positivamente pelo mercado ao fim da narrativa. A matéria apresenta o caso Ruffles, no qual a Pepsico lançou três novos sabores do produto a partir de interação com usuários de internet e de redes sociais virtuais. O texto abre espaço, também, para o enaltecimento dos parceiros corporativos da Pepsico na campanha, como agências de publicidade. Segundo a matéria, que descreve os passos da ação de marketing: 
26 de Fevereiro - A nova campanha de Ruffles é lançada em rede nacional. Por meio de redes sociais, como Twitter e Facebook, a Pepsico convida os internautas a enviar sugestões de sabores para os salgadinhos. Em um só dia, 100.000 ideias são registradas no site da marca (Matéria "Da internet para a linha de produção", 2011, p. 90).

Nos textos em questão, fica clara a estratégia de manipulação por sedução ou intimidação - concretizada em "histórias contadas" na revista -, na qual o destinador-leitor é apresentado às ferramentas de tecnologia como uma forma de acompanhar a evolução do mercado e das tendências gerenciais.

Vale observar que os riscos associados às redes virtuais não se limitam à decisão de inseri-las ou não na estratégia e nas operações da empresa. São destacados pela revista, também, os riscos do uso errado das ferramentas, como na matéria "Os blogs vão mudar seus negócios" (2006), em que, ao lado de exemplos bem-sucedidos no uso da tecnologia, figuram casos de fracasso. Nessas narrativas, tais fracassos são alvo de sanção negativa do mercado, configurando "histórias de final triste". Dessa forma, reforça-se a mensagem sobre a necessidade do domínio correto das ferramentas.

A análise diacrônica dos títulos das matérias apresenta interessante perspectiva da sucessão de ferramentas que, no discurso da revista analisada, surgem sempre como a próxima solução a ser adotada pelos gestores. Observam-se, por exemplo, as seguintes reincidências nos títulos (a) Ferramentas tecnológicas como sujeitos de orações com os verbos invadir (empresas) e mudar (negócios); (b) Expressões que designam a substituição de ferramentas: "nova mania", “o e-mail morreu”, "Que nada!”, “a nova cara”; e (c) Expressões que destacam a extrema relevância de uma ferramenta: "a Era da...”, “o poder...”, "pega um, pega geral” (alusão à trilha sonora do filme “Tropa de Elite”, foco da matéria), “... é o canal”.

Os temas gerenciais respondem às ansiedades e às inseguranças de seus respectivos leitores por intermédio de receitas prontas, fórmulas gerenciais mágicas e modismos. Confirma-se, aqui, a análise de Wood Jr. (2001, p. 105) de que isso ocorre de forma sempre repetitiva: “'Como o novo executivo salvou a empresa', 'A última palavra em software empresarial', 'Como a empresa inovadora conquistou o mercado' [...] além das matérias do tipo notícia útil: 'Como falar em público', 'Como escolher um MBA', 'Como aumentar a sua empregabilidade"”. Ao analisar o corpo das matérias, percebe-se que as ferramentas sucedidas pelas "novidades do momento" continuam a fazer parte da gama de opções tecnológicas, mas 
passam a ocupar papel secundário nas narrativas protagonizadas por consumidores e empresas.

\subsection{O nível discursivo: a concretização das narrativas}

Com base no princípio de que todo discurso procura persuadir seu destinatário de que é verdadeiro (ou falso), os mecanismos discursivos têm, em última análise, por finalidade criar a ilusão de verdade por meio de dois efeitos básicos: proximidade $v s$. distanciamento da enunciação e realidade vs. ficção (BARROS, 2006; FIORIN, 2006).

No nível da sintaxe discursiva, as variações de tipo de narrador cumprem relevante papel na criação de efeitos de sentido nos textos. A principal estratégia identificada nas matérias estudadas foi a utilização do narrador em terceira pessoa (típico do gênero jornalístico), com o recurso do narrador que dá a palavra a interlocutores (em geral, personagens do mundo corporativo ou consumidores). Tal variação concilia o afastamento do enunciador, que gera efeito de objetividade e credibilidade, com a proximidade da fala do interlocutor, cujo efeito é de ancoragem. Conforme explica Barros (2005, p. 60), apesar de o recurso sintáxico de dar voz a personagens fictícias e reais produzir efeitos de realidade ou referente, tais efeitos são

\footnotetext{
construídos mais frequentemente por meio de procedimentos da semântica discursiva e não da sintaxe, ao contrário do que ocorre com os efeitos de enunciação. $\mathrm{O}$ recurso semântico denomina-se ancoragem. Trata-se de atar o discurso a pessoas, espaços e datas que o receptor reconhece como 'reais' ou 'existentes', pelo procedimento semântico de concretizar cada vez mais os atores, os espaços e o tempo do discurso, preenchendo-os com traços sensoriais que os 'iconizam' ou fazem 'cópias da realidade'. Na verdade, fingem ser 'cópias da realidade', produzem tal ilusão.
}

É importante observar que as personagens do mundo corporativo citadas nas matérias são simulacros do leitor-enunciatário (pelo próprio perfil do leitor da revista, um executivo ou um "postulante a tal designação"), apresentadas, em geral, de forma estereotipada, o que aumenta a relevância dessa estratégia de manipulação.

Avançando na análise, a semântica discursiva é a arena ideal para compreender como determinado discurso apropria-se dos valores em circulação na sociedade e, ao mesmo tempo, 
impõe ao enunciatário novos valores que sustentem determinada visão de mundo, por meio dos procedimentos de tematização e de figurativização.

Dois grandes temas dominam as matérias analisadas: "a utilização de redes sociais virtuais como ferramentas de negócio", em especial na gestão de marketing, e "o comportamento do consumidor". Pode-se dizer que os temas são complementares e, não raro, dividem espaço em alguns textos, estando sempre presentes nas imagens ou nos textos verbais.

As figuras de maior representatividade são aquelas que compõem, em geral, as visões estereotipadas do mundo dos negócios e da tecnologia: figuras humanas, computadores, marcas de empresas e de produtos (com destaque para as marcas das próprias ferramentas). Assim, as figuras e temas presentes no corpus ratificam a inclusão da revista Exame no universo da comunicação de massa, ainda que restrita ao segmento de mídia de negócios e da indústria do management. Pode-se dizer que, para além das novidades gerenciais - nesse caso, as comunidades sociais virtuais -, a análise do nível discursivo aponta para a alimentação dos valores associados ao sucesso profissional, confirmando a visão de Micklethwait e Wooldridge (1998) e Wood Jr. e Paula (2001).

\section{Considerações finais}

O presente artigo objetivou proceder a uma aplicação do modelo teórico clássico da Semiótica Greimasiana para identificar as estratégias narrativas e discursivas adotadas pela revista Exame em seu discurso sobre as comunidades sociais virtuais. Procurou-se, portanto, evidenciar os procedimentos de manipulação do destinatário-leitor pelo destinador-revista, com base nos pressupostos teórico-metodológicos da Semiótica Discursiva de linha francesa.

Partindo do nível mais abstrato de análise (nível fundamental e narrativas da enunciação) para os mais concretos (narrativas do enunciado e nível discursivo), apresentouse o uso que a revista Exame faz de simulacros de certos sujeitos que compõem o mercado consumidores, empresas de tecnologia (figurativizadas pelas suas soluções tecnológicas, como Twitter e Facebook) e empresas de outras áreas de atuação - para construir narrativas nas quais os atores em questão interagem entre si e se revezam no papel de destinadores de "histórias" cujo objetivo é manipular o leitor, por sedução ou intimidação, a alinhar-se às recentes tendências de gestão por meio da adoção das redes sociais virtuais. 
Nesse ponto, o presente trabalho ofereceu ao leitor uma ilustração do processo de análise da comunicação sob a perspectiva da Semiótica, deixando claro que o fazercomunicativo do destinador não se restringe apenas a um fazer-saber, mas acarreta um fazercrer e um fazer-fazer, paralelo à interpretação no fazer-comunicativo do destinatário (BARROS, 2006).

Para além da abordagem meramente teórica de análise do discurso da revista Exame, ao exibir as "engrenagens do discurso", o percurso aqui empreendido ratificou diagnósticos de diversos autores sobre a mídia de negócios. Foram identificados (1) o culto de símbolos e figuras emblemáticas e (2) a crença em tecnologias gerenciais inovadoras como os principais mecanismos de racionalização das atividades e práticas de gestão que, juntos, buscam responder às ansiedades e inseguranças dos leitores por intermédio de fórmulas gerenciais (quase) mágicas e modismos.

Futuras pesquisas baseadas no aparelho teórico-metodológico da Semiótica Greimasiana podem complementar e aprofundar os resultados do presente trabalho. Nesse contexto, destacam-se possíveis análises que envolvam o plano da expressão dos textos das revistas de negócios e, em especial, seus aspectos visuais (fotografias, logomarcas e ilustrações, por exemplo).

Sentimento de falta e sentimento de urgência: pode-se argumentar que as inovações tecnológicas são manipuladas discursivamente como forma de lidar com um mundo acelerado que transforma tudo o que encontra pelo caminho em algo descartável, instantâneo e efêmero. Nesse sentido, as histórias de sucesso, as biografias de celebridades e as receitas para melhorar o desempenho apresentam-se fundamentais para gerar uma ilusória - e pretendida sensação de conforto.

\section{Notas}

1. Segundo Donadone (2000, p. 3), "a revista Exame surgiu a partir do encarte 'Negócios em Exame' que, desde 1967, era publicado dentro das revistas técnicas da Editora Abril: Máquinas e Metais, Transporte Moderno, Química e Derivados e Plástico Moderno". 


\section{Referências}

BAGOZZI, R. P.; DHOLAKIA, U. M. Intentional Social Action in Virtual Communities. Journal of Interactive Marketing, v. 16. n. 2, p. 2-21, 2002.

BARROS, D. L. P. A comunicação humana. In: FIORIN, José Luiz (Org.). Introdução à lingüística I - Objetos teóricos. São Paulo: Contexto, 2006, p. 25-53.

BARROS, D. L. P. Publicidade e figurativização. ALFA: Revista de Linguística, v. 47, n. 2, p. 11-31, 2004.

BARROS, D. L. P. Teoria semiótica do texto. São Paulo: Ática, 2005.

BARROS, D. L. P. Teoria do Discurso - Fundamentos Semióticos. São Paulo: Humanitas, 2002.

BERTRAND, D. Caminhos da semiótica literária. São Paulo: EDUSC, 2003.

CAPElle, M. C. A.; MAGeSte, G. S.; MelO, M. C. O. L.; BRITO, M. J. M. A representação feminina na mídia de negócios: um estudo com duas revistas populares especializadas em gestão. Anais do XXVII Encontro da ANPAD, Atibaia, 2003.

CASTELLS, M. A sociedade em rede. São Paulo: Paz e Terra, 1999.

DALMORO, M.; FLECK, J. P.; VENTURINI, J. C.; LAZZARI, F.; LEITE, R. C.; ROSSI, C. A. V. Twitter: uma análise do consumo, interação e compartilhamento na Web 2.0. Anais do XXXIV EnANPAD, Rio de Janeiro, 2010.

DHOLAKIA, U. M.; BAGOZZI, R. P.; PEARO, L. K. A social influence model of consumer participation in network-and small-group-based virtual communities. International Journal of Research in Marketing, v. 21, p. 241-263, 2004.

DIAS, V. T.; SECCO, G. M.; PESSOA, G. R. A.; WETZEL, U. Distinção entre as noções de empresária e 'empreendedora' na mídia de negócios: um estudo comparativo entre as revistas Exame e Fortune. Anais do XXXI Encontro da ANPAD, Rio de Janeiro, 2007. 
DONADONE, J. C. Imprensa de negócios, dinâmica social e os gurus gerenciais. Anais do I EnEO, Curitiba, 2000.

FIALHO, C. B.; LÜTZ, C. B. Análise da intenção de continuidade de uso de um sistema voluntário: em cena o fenômeno Twitter. Anais do III EnADI, Porto Alegre, 2011.

FIORIN, J. L. Elementos de análise do discurso. São Paulo: Contexto, 2006.

FIORIN, J. L. Linguagem e ideologia. São Paulo: Ática, 2004.

FLOCH, J. M. Petites mythologies de l'oeil et de l'esprit: pour une sémiotique plastique. Paris-Amsterdam: Hadès-Benjamins, 1985.

FONTANILLE, J. Semiótica do discurso. São Paulo: Contexto, 2007.

GREIMAS, A. J. De la imperfección. México: FCE, 1997.

GREIMAS, A. J.; COURTÉS, J. Dicionário de semiótica. São Paulo: Contexto, 2008.

HÉNAULT, A. História concisa da Semiótica. São Paulo: Parábola Editorial, 2006.

IBOPE Nielsen OnLine. $\quad$ Disponível em <http://www.ibope.com.br/calandraWeb/servlet/CalandraRedirect?temp=6\&proj=PortalIBOP $\mathrm{E} \& \mathrm{pub}=\mathrm{T} \& \mathrm{db}=\mathrm{caldb} \& \mathrm{comp}=$ pesquisa_leitura\&docid $>$. Acesso em: 18 fev. 2011.

KIMURA, H.; MARTIN, D. M. L.; BASSO, L. F. C. Redes sociais e o marketing de inovações. II EMA, Rio de Janeiro, 2006.

KOLLER, V. Critical discourse analysis and social cognition: evidence from business media discourse. Discourse \& Society, v. 16, n. 2, p. 199-224, 2005.

LANDOWSKI, E. Passions sans nom. Paris: PUF, 2004.

LEVY, P. Cibercultura. São Paulo: Editora 34, 1999. 
MICKLETHWAIT, J.; WOOLDRIDGE, A. Os bruxos da administração: como entender a babel dos gurus empresariais. Rio de Janeiro: Campus, 1998.

SIMÕES, R. C.; SANT'ANNA, S. R. A beleza dos cabelos crespos e cacheados: um olhar a partir de uma comunidade virtual do Orkut. Anais do XXXIV EnANPAD, Rio de Janeiro, 2010.

SIQUEIRA, M. V. S.; FREITAS, M. E. O papel da mídia especializada em negócios na reprodução do discurso organizacional em recursos humanos no Brasil. Anais do XXX Encontro da ANPAD, Salvador, 2006.

SOUZA, F. M.; FILENGA, D.; SANCHEZ, O. P. O impacto da influência social sobre a intenção de uso de sites de compras coletivas: um estudo baseado no modelo UTAUT, com usuários do Orkut, Facebook, Twitter e LinkedIn. III EnADI, Porto Alegre, 2011.

SPINK, P. Análise de documentos de domínio público. In: SPINK, M.J.P. (Org.). Práticas discursivas e produção de sentidos no cotidiano. São Paulo: Cortez, 2004.

WOOD JR., T. Organizações espetaculares. Rio de Janeiro: Editora FGV, 2001.

WOOD JR., T.; PAULA, A. P. P. A mídia especializada e a cultura do management. Organizações \& Sociedade, v. 13, n. 38, p. 91-105, 2006.

WOOD JR., T.; PAULA, A. P. P. Pop-Management. Anais do XXV ENANPAD, Campinas, 2001. 